Agar kemiskinan dapat ditanggulangi tidak saja diperlukan koordinasi antar lembaga sektoral, tetapi program kemiskinan harus terpadu dalam dan menjadi tujuan utama keseluruhan program pembangunan. Untuk itu dibutuhkan penyelarasan kebijakan dan program, program dan penganggaran, dan penentuan sasaran serta sistem penyampaiannya.

\section{Bagaimana dilakukan?}

Program penanggulangan kemiskinan bukan program yang berdiri sendiri tetapi harus menjadi bagian dari setiap sektor pembangunan dan seluruh program pembangunan. Tujuan pengentasan kemiskinan tiap-tiap instansi harus dipertimbangkan dalam semua kegiatan pada semua tingkat organisasi.

Untuk mengarus-utamakan program kemiskinan, Kelompok Kerja Perencanaan Komite Penanggulangan Kemiskinan telah menyusun kerangka proses sebagai berikut:

- Penyamaan Persepsi Sumber Permasalahan Kemiskinan

- Penyelarasan antara strategi, kebijakan, program, penentuan sasaran, sistem penyampaian dan sumber pendanaan

- Sinkronisasi program dan penganggaran:

o antar Departemen/LPND,

- antar pemerintah, swasta dan masyarakat, - antara daerah dan pusat

- Pembiayaan yang berpihak pada si miskin

- Perubahan dalam memaknai anggaran, bukan sebagai anggaran pemerintah tetapi sebagai anggaran publik

- Ketersediaan dana sesuai prioritas program

- Ketepatan input dana dan proses

- Sumber dana: pemerintah (APBD, DAU, DAK), swasta dan masyarakat

- Pemantauan dan Evaluasi yang memperhatikan bukan saja indikator masukan dan keluaran tetapi juga indikator hasil dan dampak.

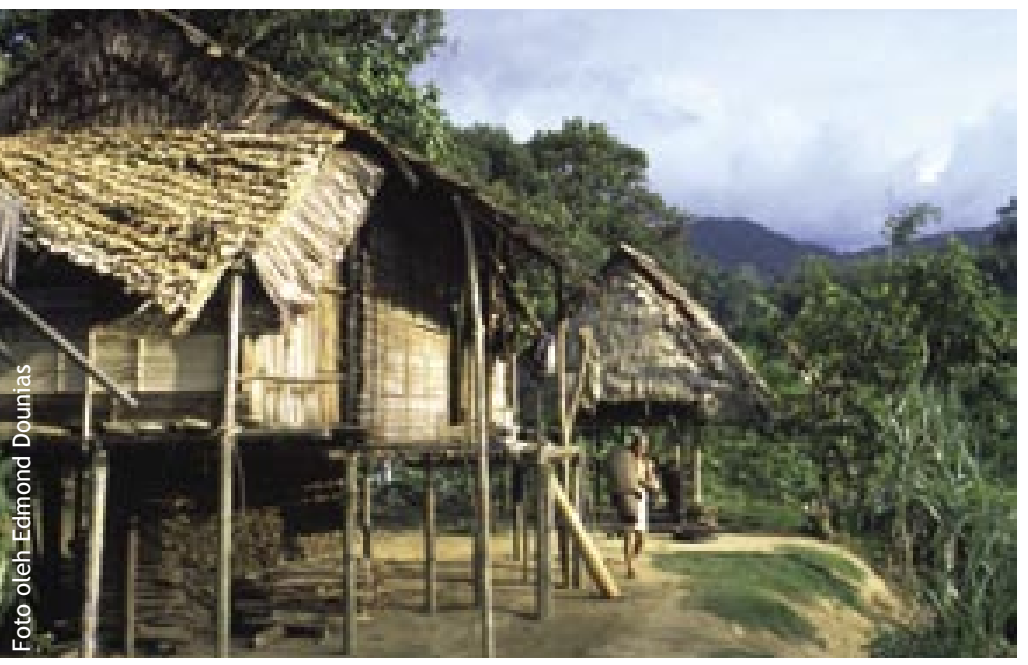

Atau dengan kata lain, untuk memastikan program penanggulangan kemiskinan menjadi arus utama, kita harus memperhatikan "pangkal maupun ujung pipa”, yaitu tahap perencanaan, penganggaran maupun tahap pemantauan dan evaluasi pembangunan.

\section{Tahap perencanaan}

Setiap negara yang tergolong memiliki pendapatan rendah saat ini diminta untuk menyiapkan Poverty Reduction Strategic Paper (PRSP) atau rencana strategis penanggulangan kemiskinan $(\mathrm{SPK})^{3}$. Di Indonesia, Bappenas bersama Komite Penanggulangan Kemiskinan (KPK) nasional mengkoordinir pembuatan dokumen tersebut. Setiap daerah juga telah membentuk KPK yang diharapkan menyusun strategi penanggulangan kemiskinan daerah (SPKD) berdasarkan status dan penyebab kemiskinan di wilayah masing-masing.

Beberapa daerah dilaporkan telah atau sedang menyusun SPKD, namun ada kecenderungan bahwa SPKD terpisah dari produk-produk perencanaan daerah (i.e. APBD, RKPD, PRJM dan RPJP). Kecenderungan ini mengisyaratkan bahwa SPK masih dilihat sebagai "produk perencanaan sampingan“. Padahal SPK bersifat lintas sektoral yang melibatkan hampir seluruh satuan kerja pelayanan di daerah. Karena perencanaan keuangan dikoordinir oleh Bappeda dan Sekretariat Daerah ${ }^{4}$, maka SPK seringkali tidak tersinergi dalam perencanaan keuangan. Dengan kata lain, kegiatan penanggulangan kemiskinan dilihat sangat sempit, terbatas pada kegiatan pengembangan ekonomi dan program bantuan kemanusiaan (misalnya bantuan beras, asuransi kesehatan, beasiswa, dan sebagainya), sehingga terpisah dengan program pembangunan pada sektor lain (misalnya sumberdaya alam, sosial, politik) yang sebenarnya sangat mempengaruhi lingkungan kehidupan masyarakat.

SPKD sepantasnya tidak menjadi dokumen perencanaan yang terpisah dengan dokumen perencanaan daerah lainnya. Strategi penanggulangan kemiskinan daerah seharusnya menjadi roh dari rencana pembangunan daerah.

\section{Tahap Penganggaran}

Dengan sistem pengelolaan anggaran berbasis kinerja (performance based budget), setiap penganggaran harus memiliki target kinerja yang jelas ${ }^{5}$. Setiap satuan anggaran kegiatan harus mencantumkan indikator-indikator kinerja yang mencakup indikator masukan, hasil, manfaat dan dampak. Sistem penganggaran berbasis kinerja ini adalah awal yang baik untuk melakukan pengawasan kinerja, sehingga pengawasan pembangunan tidak terbatas pada tujuan akuntabilitas. 
Jika sistem penganggaran berbasis kinerja ini ditindaklanjuti dengan sistem pemantauannya, maka kita memiliki pintu masuk yang sangat efektif untuk menjadikan penanggulangan kemiskinan sebagai arus utama pembangunan. Caranya adalah dengan mempengaruhi indikator kinerja agar sesuai dengan indikator yang digunakan pada pemantauan kemiskinan masyarakat.

\section{Tahap pemantauan dan evaluasi}

Sistem pemantuan dan evaluasi pemerintah daerah seharusnya disesuaikan dengan sistem perencanaan dan penganggaran berbasis kinerja yaitu dengan cara memantau dan mengevaluasi empat tingkatan indikator: masukan, hasil, manfaat dan dampak ${ }^{6}$. Pemantauan masukan dan hasil merupakan fungsi dari Bappeda dan Bawasda. Bappeda lebih berfokus pada pemantauan hasil (misalnya pemenuhan hasilhasil proyek berdasarkan spesifikasi) sedangkan Bawasda pada pemantauan masukan (misalnya keuangan dan sumberdaya lain). Pemantauan manfaat dan dampak selama ini hampir tidak pernah dilakukan.

Pemantauan kemiskinan dapat memenuhi kebutuhan ini melalui pemantauan: (1) pemenuhan kebutuhan dasar; (2) lingkungan kehidupan mendukung.

Pemantauan kebutuhan dasar bertujuan untuk memastikan masyarakat dapat memenuhi kebutuhan dasar dan dapat mencakup tiga aspek yaitu: gizi dan kesehatan, kekayaan materi, dan aspek pengetahuan. Pemantauan lingkungan bertujuan untuk memastikan bahwa masyarakat memiliki peluang untuk terus menerus memperbaiki kualitas kehidupannya sendiri. Ada empat aspek, yaitu: lingkungan politik, sosial, ekonomi dan alam (POLEKSAL) ${ }^{7}$. Pemerintah daerah harus mengembangkan indikator untuk masing-masing aspek yang cocok dengan situasi lokal dan sesuai dengan prinsip-prinsip pada tingkatan nasional dan internasional, dan menjadi bagian tidak terpisahkan dalam sistem perencanaan, penganggaran dan pemantauan.

Seluruh sistem pemantauan tersebut harus membuka partisipasi masyarakat seluasluasnya. Dalam pemantauan masukan dan hasil, masyarakat dapat langsung berpartisipasi dengan cara memantau jalannya kegiatan pembangunan di daerahnya. Hal ini hanya mungkin dilakukan jika ada keterbukaan informasi, jalur-jalur yang efektif untuk penyampaian masukan serta hak, kesadaran dan kemampuan masyarakat untuk berpartisipasi dalam pemantuan. Sedangkan dalam pemantauan kemiskinan, masyarakat dapat berperan serta sebagai pendata dan sumber informasi dalam kegiatan pendataan.

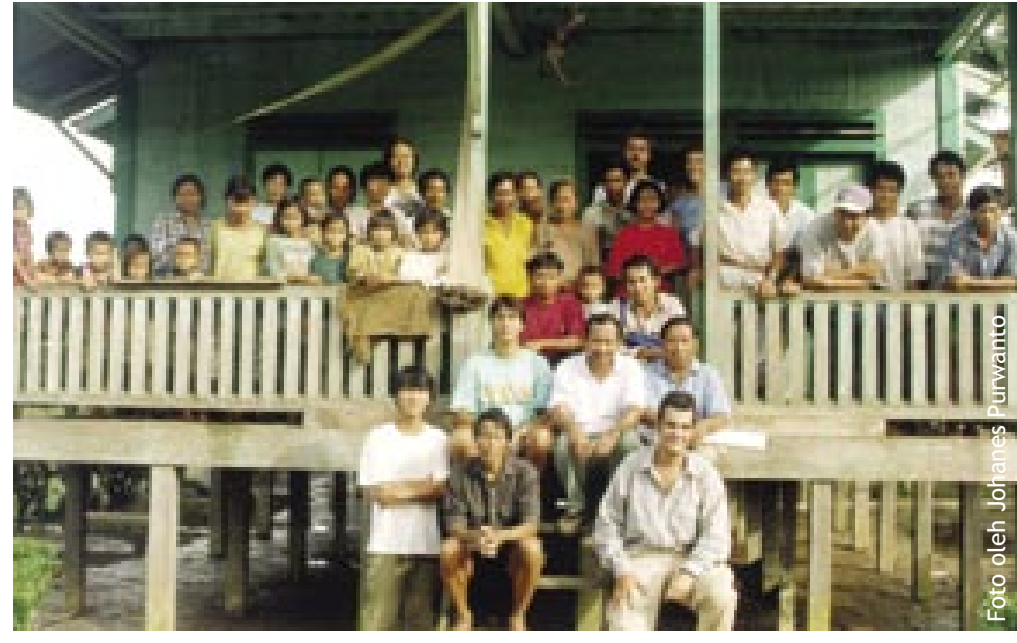

Selain pemantauan pada empat tingkatan indikator di atas, ada baiknya pemerintah daerah melakukan kajian tentang hubungan sebab akibat antara hasil dengan manfaat dan dampak. Hal ini penting untuk mengerti hasil yang mana mempengaruhi dampak yang mana dan bagaimana hal tersebut dipengaruhi. Selain itu, kajian ini juga dapat membantu memahami efektifitas hasil-hasil kegiatan pembangunan dan pengaruh dari stakeholder lain di daerah. Hasil kajian ini akan sangat membantu pemerintah daerah untuk memahami strategi kebijakan pembangunan yang efektif sesuai dengan kondisi daerahnya guna meningkatkan kesejahteraan masyarakat.

\section{Pengaturan kelembagaan}

Pembenahan sistem perencanaan, penganggaran serta pemantauan dan evaluasi seperti telah dijelaskan di atas tidak akan efektif jika tidak didukung oleh kelembagaan pemerintah daerah. Satuan-satuan kerja dalam pemerintah daerah harus berjalan sesuai dengan tugas pokok dan fungsinya. Pengarusutamaan kemiskinan harus diletakkan pada satuan kerja yang bertanggungjawab dalam pelayanan internal yaitu Sekretariat Daerah, Bappeda dan Bawasda. Bappeda dan Bawasda berfungsi mengelola sistem pemantauan sampai dengan merumuskan usulanusulan kebijakan, sedangkan Sekretariat Daerah berfungsi mengkoordinasikan serta mengkaji usulan-usulan tersebut untuk disampaikan pada kepala daerah.

Seluruh pemantauan dan pengkajian tersebut tidak akan ada manfaatnya jika tidak ada koordinasi yang baik antar kegiatan pemantauan. Satu sistem basis data yang mudah diakses dan yang relatif user friendly harus diciptakan agar data yang didapatkan dalam sistem pemantauan tersimpan dan terkoordinasi dengan baik sehingga dapat dimanfaatkan dengan mudah. 


\section{Penentuan urusan wajib pemerintah daerah}

UU No.32/2004 tentang Pemerintahan Daerah mengatur tentang urusan-urusan pemerintahan yang wajib dijalankan oleh pemerintah daerah. Sambil menunggu peraturan pemerintah turunan undang-undang tersebut, kami mengusulkan beberapa fungsi yang dapat dipertimbangkan sebagai urusan wajib. Fungsi-fungsi ini diidentifikasi berdasarkan penelitian sebab akibat kemiskinan di Kabupaten Kutai Barat, Kalimantan Timur ${ }^{8}$.

1. Pengelolaan dan pelayanan kesehatan masyarakat

2. Pengelolaan dan pelayanan pendidikan formal dan informal termasuk pemberdayaan pengetahuan asli yang relevan dengan kesejahteraan masyarakat

3. Pengelolaan lingkungan hidup dan pelayanan kebersihan lingkungan

4. Pelayanan dan pengelolaan sistem administrasi pertanahan dan kepemilikan atas sumber daya alam yang sesuai dengan budaya lokal

5. Pengelolaan dan pelayanan kependudukan dan catatan sipil

6. Administrasi umum pemerintahan dan hubungan pemerintah-masyarakat

7. Pelayanan dan pengelolaan upaya penanaman modal, industri dan ketenagakerjaan

8. Pengelolaan dan pelayanan sarana dan prasarana transportasi dan perhubungan

9. Pelayanan lembaga keuangan masyarakat (yang mengutamakan pendidikan budaya uang dan pengelolaan keuangan rumahtangga) dan bantuan teknis pengembangan usaha

10. Pengelolaan sumberdaya air dan pelayanan kebutuhan air sehat

11. Pelayanan partisipasi masyarakat dalam pengembangan hukum dan perundangundangan termasuk distribusi produk-produk hukum dan perundangan
12. Pengelolaan dan pelayanan jaring pengaman sosial, yang meliputi: ketahanan pangan, pemenuhan komoditas rumahtangga strat egis, hubungan sosial kemasyarakatan, dan penyelenggaraan ketertiban umum dan ketenteraman masyarakat

13. Pengelolaan sumber daya alam dan usaha pertanian (konservasi dan pemanfaatan), terutama untuk sektor-sektor strategis yaitu hutan, tambang, perikanan, pertanian tanaman pangan dan perkebunan

14. Penguatan kelembagaan masyarakat

15. Pelayanan dan pengelolaan sistem informasi dan komunikasi masyarakat (memastikan arus informasi dan sistem komunikasi dari luar ke dalam dan sebaliknya, dan antar masyarakat)

16. Pelayanan terhadap lembaga penyelesaian persengketaan masyarakat dan pemantauan ketegangan sosial

17. Pelayanan kesenian, hiburan dan pariwisata

18. Pelayanan spiritual dan promosi cara berkehidupan yang baik

19. Penanganan bencana alam skala daerah

20. Pelayanan pemukiman dan perumahan rakyat.

Daftar usulan fungsi di atas hanya terbatas pada fungsi pelayanan masyarakat, tidak memasukan fungsi-fungsi pelayanan internal pemerintahan seperti perencanaan daerah. Daftar fungsi layanan internal dapat mengacu pada hasil analisis pengembangan kapasitas pemerintahan daerah yang saat ini sedang dikembangkan di banyak tempat. Daftar nomor 1 sampai dengan 7 secara eksplisit tercantum di dalam UU 32/2004, sedangkan yang lainnya tidak tercantum secara eksplist tetapi masih mungkin masuk dalam beberapa kategori lain (misalnya layanan lembaga keuangan masyarakat dapat masuk dalam kategori koperasi).

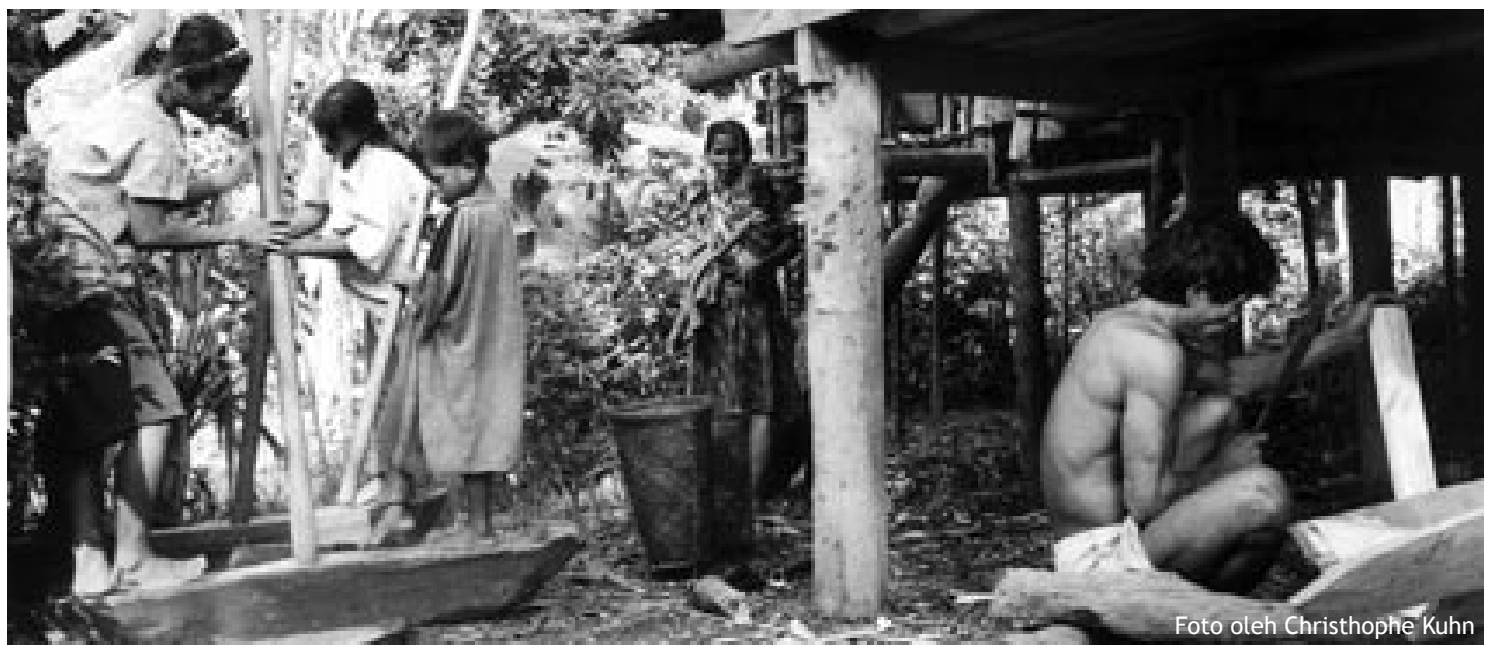




\section{Apa syarat agar pengarus- utamaan dapat efektif?}

Pada akhirnya, pengarusutamaan kemiskinan hanya akan efektif jika:

1. Ada keinginan politik

2. Seluruh sistem perencanaan, pemantauan dan evaluasi pemerintahan daerah terintegrasi dengan baik

3. Adanya tata kelola pemerintahan yang baik

4. Adanya kepemimpinan pemerintahan yang efektif mengelola pembangunan

5. Tidak ada ego sektoral dan ego tingkatan pemerintahan (pusat versus daerah), yang ada sinergi menuju visi yang menjadi komitmen bersama

6. Adanya pembagian peran yang jelas dan adil antara pelaku dalam penanggulangan kemiskinan, yaitu pemerintah, swasta dan masyarakat

7. Adanya pembagian peran yang jelas dan adil antara pelaku dalam penanggulangan kemiskinan, yaitu pemerintah, swasta dan masyarakat

8. Adanya pembagian peran dan tanggung jawab yang jelas dan adil antara sektor-sektor teknis pemerintahan daerah.

\section{Catatan kaki}

1 Penasehat Kepala Bappenas, pada jumpa pers di Sanur, Bali, 3 Augustus 2004

2 Binny Buchory, Direktur Eksekutif Perkumpulan PraKarsa dalam harian Kompas 9 April 2005

3 Lihat: http://www.imf.org/external/np/exr/ facts/prsp.htm

4 Terutama bagi daerah yang tidak membentuk Badan Pengelolaan Keuangan Daerah
5 Diperkenalkan pertama kali lewat SK Mendageri No.29 tahun 2002 tentang Pedoman Pengurusan, Pertanggungjawaban dan Pengawasan Keuangan Daerah Serta Tata Cara Penyusunan Anggaran Pendapatan dan Belanja Daerah, Pelaksanaan Tata Usaha Keuangan Daerah, dan Penyusunan Perhitungan Anggaran dan Pendapatan Belanja Daerah. Yang kemudian diperkuat oleh UU No.17 tahun 2003 tentang Keuangan Negara dan peraturan perundangan tentang keuangan negara yang disahkan setelah tahun 2003.

6 Pasal 153 UU 32/2004 tentang Pemerintahan Daerah mewajibkan adanya keterkaitan dan konsitensi antara perencanaan, penganggaran, pelaksanaan dan pengawasan pembangunan.

7 Dua pemantauan ini mirip dengan pepatah bijak yang sering kita dengar "jangan berikan ikan, tapi berikan kail”. Pemberian ikan adalah perumpamaan untuk pemberian kebutuhan dasar, ini tidak salah karena orang yang sedang kelaparan pasti tidak mungkin dapat mancing walaupun ada kail. Tapi pemberian ikan terus menerus tidak akan membuat orang mandiri, kita harus memberikan hak untuk memancing (politik), kail (aset ekonomi), sungai yang bebas dari konflik (sosial) serta sungai yang sehat (alam). Oleh karena itu ikan dan kail sama-sama penting pada situasinya masingmasing.

8 Lihat Gönner, C., Cahyat, A. and Haug, M. Draft 2005. Does decentralization reduce rural poverty? Well-being trends in Kutai Barat 1999 - 2004. Draft version dated 10th March 05. CIFOR, Bogor. 


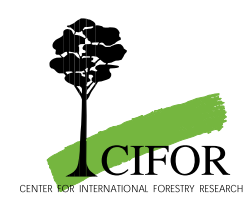

Bundesministerium für

wirtschaftliche Zusammenarbeit

und Entwicklung

Center for International Forestry Research, CIFOR

Alamat kantor: Jalan CIFOR, Situ Gede, Sindang Barang Bogor Barat 16680, Indonesia.

Alamat surat: P.O. Box. 6596 JKPWB, Jakarta 10065 Indonesia
Tel: +62(251) 622622 Fax: +62(251) 622100

E-mail: cifor@cgiar.org

Website: www.cifor.cgiar.org

Foto sampul oleh: Nicolas Cesard dan Eva Wollenberg

Program Forests and Governance di CIFOR mengkaji cara pengambilan dan pelaksanaan keputusan berkenaan dengan hutan dan masyarakat yang hidupnya bergantung dari hutan. Tujuannya adalah meningkatkan peran serta dan pemberdayaan kelompok masyarakat yang kurang berdaya, meningkatkan tanggung jawab dan transparansi pembuat keputusan dan kelompok yang lebih berdaya dan mendukung proses-proses yang demokratis dan inklusif yang meningkatkan keterwakilan dan pengambilan keputusan yang adil di antara semua pihak. 